\title{
Ongoing Phenotypic and Genotypic Diversification in Adaptively Radiated Freshwater Crabs from Jamaica
}

\author{
Christoph D. Schubart, Tobias Weil, Jesper T. Stenderup, \\ Keith A. Crandall, and Tobias Santl
}

\begin{abstract}
The Caribbean island of Jamaica is home to a lineage of crabs (Crustacea: Decapoda: Brachyura: Sesarmidae) which have colonized the most unusual terrestrial habitats. Today, they can be found nesting in bromeliad leaf axils or empty snail shells, scurrying on the forest floor or among dry rock rubble, climbing on walls of deep cave systems, or digging burrows in the banks of mountain streams. In order to facilitate survival of their offspring in these remarkable and new habitats, complex behavioral adaptations have evolved, including feeding and protecting the offspring, and transport of empty snail shells into the nursery to buffer the $\mathrm{pH}$ and provide the necessary calcium carbonate [summarized in Diesel (Proc Roy Soc Lond B 264:1403-1406, 1997), Diesel and Schubart (Evolutionary ecology of social and sexual systems: crustaceans as model organisms. Oxford University Press, New York, pp 365-386, 2007)]. No other American sesarmid crab species shows this degree of terrestriality and elaborate brood care behavior. Instead, the most related species typically are inhabitants of marshes and mangroves and reproduce by releasing their larvae into the ocean, without any additional paternal obligation. Molecular phylogenetic analyses revealed that the Jamaican endemic sesarmids are monophyletic and thus the outcome of a single colonization event, which took place approximately 4.5 million years ago and was followed by a rapid radiation, speciation, and adaptation to ecological niches, which have not been used by crabs in any other parts of the world and required evolution of complex behavioral strategies to render survival in these habitats possible (Schubart et al. Nature 393:363-365, 1998a). This system can be considered a classic example of
\end{abstract}

C.D. Schubart ( $\square)$, T. Weil, and T. Santl

Biologie 1, Institut für Zoologie, Universität Regensburg, 93040 Regensburg, Germany

e-mail: christoph.schubart@biologie.uni-regensburg.de

J.T. Stenderup

Biologie 1, Institut für Zoologie, Universität Regensburg, 93040 Regensburg, Germany

Natural History Museum of Denmark, University of Copenhagen, 1350 København, Denmark

K.A. Crandall

Department of Biology, Brigham Young University, Provo, UT 84602-5255, USA 
an adaptive radiation of comparatively young age. It calls for research concerning the mechanisms and the pace of evolution to generate these highly specialized forms. In the present paper, we provide new data on evolutionary processes at the intraspecific level, which may help to understand the potential of diversification in these crabs. Furthermore, published and unpublished data available for these specialized crabs are summarized, giving evidence for the astounding diversity of evolutionary strategies and the dimension of biodiversity beyond the species level.

\section{Introduction}

The insight by Charles Darwin that animals and plants thriving on our planet are subject to continuous change as a result of natural selection and adaptation has been decisively influenced by endemic ground finches (Emberizidae: Geospizinae) from the Galapagos Islands. Thirteen of these birds were collected by Darwin in autumn 1835 during the voyage of the HMS Beagle and, shortly after the return to London, the ornithologist John Gould communicated to Darwin that the finches and mockingbirds from the different islands were distinct species and not just varieties (Sulloway 1982). The realization that each island had its own set of species with different adaptations prompted Darwin to write "Seeing this gradation and diversity of structure in one small, intimately related group of birds, one might really fancy that from an original paucity of birds in this archipelago, one species had been taken and modified for different ends" (Darwin 1845), thus considering a "transmutation of species" and later culminating in publication of his theory of natural selection (Darwin 1859). Nowadays, the Geospizinae are commonly referred to as "Darwin's finches" and are the most often cited example for so-called adaptive radiations.

Adaptive radiations thus belong to the earliest evidences for biological evolution and, next to Darwin's finches, honey creepers (Drepanidinae), fruit flies (Drosophilidae), and silverswords (Madiinae) from Hawaii, Anolis lizards (Iguanidae) from the Caribbean islands, as well as cichlid fishes from East African lakes are frequently reported and impressive examples of such evolutionary events (Schluter 2000). According to this author, an adaptive radiation is "the evolution of ecological and phenotypic diversity within a rapidly multiplying lineage". Possible factors causing adaptive radiations could be (1) the combination of diverse habitat and competition (divergent selection), (2) the evolution of novel advantageous features (innovation), and/or (3) the presence of ecological opportunity, like new habitats, combined with a lack of predation or competition (unoccupied niches). In most cases, such increase of diversity results in a number of species (or other taxa) of approximately the same age.

Schluter (2000) proposed four criteria to define and recognize adaptive radiations: (1) common ancestry, (2) rapid speciation, (3) phenotype-environment correlation, and (4) trait utility. The first two criteria are of phylogenetic nature, while the latter two criteria correlate present morphological and ecological characteristics 
with natural selection. Schubart et al. (1998a) gave phylogenetic evidence for common ancestry and rapid speciation in a monophyletic group of endemic crabs of the family Sesarmidae from Jamaica, inhabiting diverse terrestrial and freshwater environments. This and previous studies (Hartnoll 1964; Schubart et al. 1997) provide examples of phenotype-environment correlation, suggesting that morphological differences between the species can be related to their habitats (e.g., flattened carapace in bromeliad crabs and elongated tactile legs in cave crabs). Trait utility, i.e., "evidence that morphological and physiological traits of species are indeed useful where they are employed" (Schluter 2000: p.11) becomes obvious when observing these animals in the field; for example, a bromeliad crab retreating into the narrowest part of a leaf axil, a mountain stream crab constructing burrows with its stout, strong and setose ambulatories, or a cave crab exploring its three dimensional environment in the dark by stretching its slender elongated legs in all directions (personal observations; Diesel and Schubart 2000: figs. 3 and 6). Also, differences in the evolution of abbreviated development (Hartnoll 1964; González-Gordillo et al. 2010) and of hyperosmotic regulation (Schubart and Diesel 1999) compared to their marine confamilial relatives can be considered as traits providing physiological and morphological advantages in the new environment. We thus consider all criteria fulfilled to classify the radiation of Jamaican land-dwelling crabs adaptive.

As a consequence of the prolonged time which is normally necessary for completion of speciation processes, most of our available evidence for adaptive radiations is post-hoc, i.e., the outcome of adaptive radiations. In the scientific literature, the term "adaptive radiation" is therefore mostly used when referring to past multiple speciation events with simultaneous ecological divergence. However, adaptive radiation is first manifested as variation among populations. Therefore, the study of ecological and genetic divergence between populations is a promising approach of gaining new insights into the fundamental processes that cause adaptive radiations (e.g., Huber et al. 2007). Post-hoc reconstructions and interpretations of adaptive radiations are often very difficult due to the relative rapidity of the involved speciation processes (e.g., Schubart et al. 1998a). Fast splits into several species may not allow diagnostic morphological or molecular characters to be established in the different evolutionary lineages. Morphological and genetic variation within the ancestral population is randomly distributed among the different lineages and, even with an absolute lack of gene flow, it will take a considerable evolutionary time before these lineages can be told apart. If this "lineage sorting" process (see Neigel and Avise 1986) is not completed, it may hinder reconstructions from rapid or recent speciation events.

The present study provides examples of ongoing morphological and genetic diversification within some of the Jamaican endemic freshwater crabs that evolved by adaptive radiation between 3 and 4.5 million years ago. This shows once more that in evolution nothing is ever completed but is in constant flux. Species formation and biological diversification is a continuous process from which we can only witness a very limited time window, attempting to understand the principles of the evolution of biodiversity. 


\section{Phenotypic Modification of Body Form in Response to Cave-Living}

Jamaican caves are inhabited by different species of crabs, from which only one, Sesarma verleyi Rathbun 1914, is an obligatory troglobiont (i.e., restricted to caves), whereas others are troglophilic freshwater crabs that can be encountered in caves as well as outside them. One such example is Sesarma windsor Türkay and Diesel 1994. Originally described from the entire western-central region of Jamaica (Türkay and Diesel 1994), the occurrence of this species was later restricted to a single cave system in central Jamaica, its type locality Printed Circuit Cave (Trelawny), and the species was redescribed by Schubart et al. (1997), after recognizing morphological differences from other populations of freshwater crabs previously included within $S$. windsor. At that point, most of its morphological differences, as for example lighter coloration, longer appendages, smaller eye stalks, flatter and broader body form, were attributed to a cave-dwelling mode of life (Schubart et al. 1997), similar to, but not as pronounced as, in S. verleyi. Additional geographic sampling procured material which revealed that $S$. windsor occurs in four neighboring river systems (Hectors River, Quashies River, Mouth River, and Cave River) along the northeastern fringe of the Cockpit Country (Trelawny, Central Jamaica) (Schubart and Koller 2005) (Fig. 1). These rivers have in common that their beds are only in part exposed to the surface. All of them are characterized by water seepage into the calcareous rock and probable reappearance in the coastal plains (e.g., Rio Bueno) or along the submerged island shelf. The subterranean connections between these rivers still remain mostly unexplored. S. windsor was encountered in the surface streams of these rivers as well as in the entrance area of caves or deep within the accessible caves. Therefore, the question remained whether morphological characteristics as described by Schubart et al. (1997) are unique for the cave population or are a general characteristic of this species. Expressed differently: is the presumed troglophilic morphology of

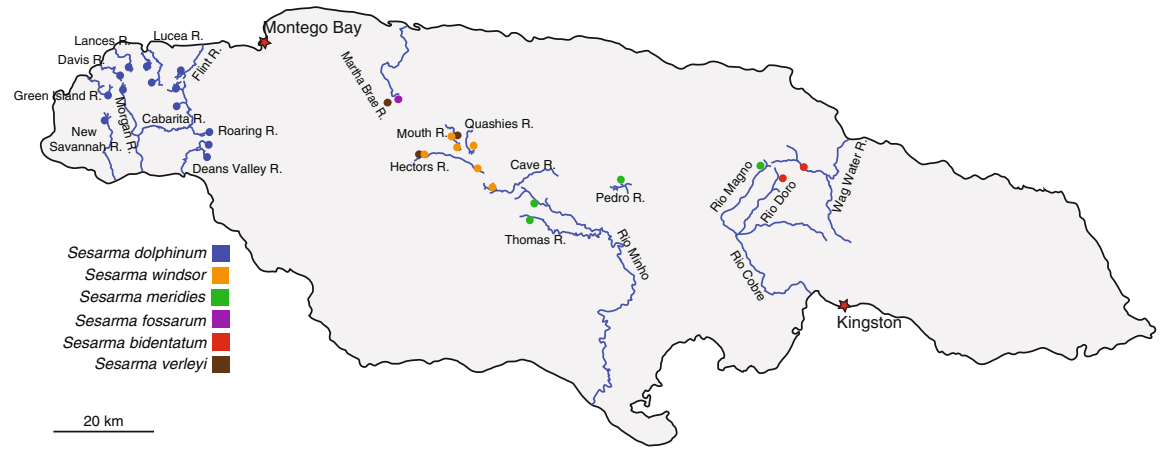

Fig. 1 Map of Jamaica showing selected rivers and localities where species for the current study have been collected 
S. windsor consistent and also found in representatives thriving in surface waters, or are there short-term genetic or even phenotypic mechanisms allowing rapid evolution of a body form which is favorable in cave habitats?

To investigate this question, we compared morphometry and genetics of crabs from the Mouth River in central Jamaica, which has extended subterranean passages (Printed Circuit Cave, Harties Cave, Mouth River Maze) directly connected to nearby surface waters. Crabs from the subterranean and surface populations seem to differ in their overall morphological appearance. However, lack of gene flow with only a few meters distance between the populations appears unlikely and could only be explained by strong ecological exclusion. Genetic differentiation at such close geographic distances would be a striking example of parapatric separation, whereas genetic identity would represent an interesting case of phenotypic plasticity in the arthropod world.

\subsection{Materials and Methods}

Specimens of Sesarma windsor were collected over an 11-year period between 1993 and 2003 from a subterranean stream inside the Printed Circuit Cave (also known as Corner Cave or John Foden Cave) and outside the cave from the Mouth River. The Printed Circuit Cave is located to the southeast of the Mouth River sink near the village of Rock Spring and stretches across approximately $610 \mathrm{~m}$ length more or less parallel to the Mouth River. Like most of the other limestone caves in the Cockpit karst, the Printed Circuit Cave has many sinter terraces lining the river channel of the little cave stream. These sinter terraces are the habitat for the crabs living in the cave, while crabs outside the cave inhabit the beds and banks of the rivers. Collections were also carried out in the neighboring Quashies River, in the vicinity of the village Stettin (eastern Cockpit Country, Trelawny Parish). Freshwater crabs were killed on ice and preserved in $75-90 \%$ ethanol for subsequent measurements and genetic analyses.

\subsubsection{Morphometric Data}

Altogether, 58 adult crabs of both genders were available for the statistical analyses of morphometric data. Measurements of the studied material included the carapace width at the epibranchial tooth (CWT), the maximum width of the carapace $(\mathrm{CW})$, the carapace length $(\mathrm{CL})$, the body height $(\mathrm{BH})$, the maximum width of the pleon (PW), the interorbital width (IOW), the length of the epibranchial tooth (ET), the length of the dactylus (DaL), the length $(\mathrm{PrL})$, and the height of the propodus $(\mathrm{PrH})$ from the larger chela, the merus length of the larger cheliped (MerL), the width (MW), and length (ML) of the meri of all walking legs (pereiopods 2-5) and the ventral length (ischium-dactylus) of the extended fourth pereiopod (4PpL). The data were tested for fit to a normal distribution by the Kolmogorov-Smirnov-Test 
(Statistica, version 6.0). Because of the sexual dimorphism, measurements for chelae and pleon were tested separately for fit to a normal distribution for each gender. Statistical differences between ratios of these variables were tested with a $t$ test. A discriminant analysis was carried out for an accurate differentiation between populations by choosing 14 sex-unrelated log-transformed morphometric variables. Hereby, the number of specimens was reduced to 47 as a consequence of missing variables in the overall dataset caused by absence of different body appendages in some specimens (e.g., single walking legs). Six specimens of $S$. windsor from the neighboring Quashies River were included as an outgroup and the discriminant analysis was carried out with Statistica. The variables PW, DL, $\mathrm{PrL}, \mathrm{PrH}$, and $4 \mathrm{PpL}$ were excluded from the discriminant analyses due to evident sex-dependent differences in size.

\subsubsection{Genetic Data}

Genomic DNA was isolated from muscle tissue of walking legs from 40 crabs (20 from the cave and 20 from outside) using the Puregene (Gentra Systems) extraction kit. Isolated DNA was precipitated with $100 \%$ ethanol, desalted with $70 \%$ ethanol, dried, and resuspended in TE-buffer. Selective amplification of a 1,059-basepair region from the mitochondrial cytochrome oxidase subunit I (Cox1) gene was carried out by polymerase-chain-reaction (PCR) with 35-40 cycles and the following temperature profile: $45 \mathrm{~s}$ denaturing at $94^{\circ} \mathrm{C}, 1 \mathrm{~min}$ annealing at $48-56^{\circ} \mathrm{C}$, and $1 \mathrm{~min}$ extension at $72^{\circ} \mathrm{C}$, preceded and concluded by $5 \mathrm{~min}$ initial denaturing and $10 \mathrm{~min}$ final extension. The following primers were used: COL6b (5'- ACA AAT CAT AAA GAT ATY GG-3'; Schubart and Huber 2006), COL8 (5'-GAY CAA ATA CCT TTA TTT GT-3'; Schubart 2009), CO1f (5'-CCT GCA GGA GGA GGA GAY CC-3'; Palumbi et al. 1991) as forward primers and COH6 (5'- TAD ACT TCD GGR TGD CCA AAR AAY CA-3'; Schubart and Huber 2006), COH8 (5'-TGA GGR AAA AAG GTT AAA TTT AC-3'; Schubart 2009), COH4 (5'-AAR RAT CCT RAD TTR CCA TAY CC-3'; Mathews et al. 2002), and CO1a (5'-AGT ATA AGC GTC TGG GTA GTC-3'; Palumbi et al. $1991)$ as reverse primers. PCR reactions were carried out in $25-\mu \mathrm{l}$ volumes containing forward and reverse primers $(1.25 \mu \mathrm{l}$ of $20 \mu \mathrm{M}), 1.25 \mathrm{mM}$ dNTPs, $25 \mathrm{mM}$ magnesium chloride, $10 \times$ buffer, $1 \mathrm{U} / \mu \mathrm{l}$ Taq polymerase (MBI Fermentas), template DNA, and Millipore water. PCR products were purified with Millipore Montage ${ }^{\mathrm{TM}}$ PCR Centrifugal Filter Devices (Millipore) prior to cycle-sequencing. Sequence products were ethanol precipitated, resuspended in $\mathrm{ddH}_{2} \mathrm{O}$, and run on an ABI Prism ${ }^{\text {TM }} 310$ Genetic Analyzer (Applied Biosystems/Perkin Elmer) automated sequencer. Forward and reverse strands were sequenced for all samples. The sequences were analyzed with the program ABI Sequencing Analyses ${ }^{\circledR} 3.4$ (Applied Biosystems) and sequence data aligned unambiguously (no indels) with the multisequence editing software XESEE (Cabot and Beckenbach 1989). Sequences of the different haplotypes have been deposited in the EMBL database (FN395290FN395305). 
Genetic heterogeneity within the populations was estimated as haplotype diversity ( $h=1-\sum f \mathrm{i}^{2} ; f \mathrm{i}$ being the frequency of the haplotype $\mathrm{i}$; Avise, 2004). Pairwise $\phi_{\mathrm{ST}}$ values among populations and analysis of molecular variance (AMOVA) were calculated with Arlequin version 3.1 (Excoffier et al. 2005). The phylogenetic relationships among haplotypes are graphically represented with a statistical parsimony network using the algorithm outlined in Templeton et al. (1992) and the software TCS (phylogenetic network estimation using statistical parsimony; Clement et al. 2000).

Three microsatellite loci currently available for the Jamaican Sesarmidae (Marcadé et al., unpublished; Heine 2006) were amplified for 25 animals from the caves versus 25 from outside the cave.

\subsection{Results}

\subsubsection{Morphometrics}

Highly significant morphometric differences between individuals of Sesarma windsor from the Printed Circuit Cave and the Mouth River population were revealed in all comparisons: ratios of single characters, sex specific characters, and in the overall discriminant analyses. The most obvious character to distinguish specimens of both populations is the length of the walking legs in both sexes, with specimens of the cave population having longer and more slender legs than those of the river population. The relative length of the fourth pereiopod in relation to the carapace width $(4 \mathrm{PpL} / \mathrm{CW})$ is $1.75 \pm 0.04$ in the cave animals $\left(\mathrm{N}_{\mathrm{PC}}=18\right)$ and $1.65 \pm 0.06$ in the Mouth River $\left(\mathrm{N}_{\mathrm{MR}}=24\right)$. There are also highly significant differences in the length to width proportions of the meri of all walking legs, with cave animals always showing values above 2.5 and surface inhabitants below. These differences are so pronounced that standard deviations are non-overlapping, with the exception of the last pair of walking legs (Table 1). Furthermore, crabs of the river population have a significantly broader front in relation to the carapace width $\quad\left(\mathrm{IOW} / \mathrm{CW}=0.48 \pm 0.01, \quad \mathrm{~N}_{\mathrm{MR}}=29 ; \quad \mathrm{IOW} / \mathrm{CW}=0.47 \pm 0.01, \quad \mathrm{~N}_{\mathrm{PC}}\right.$ $=28$ ) and a significantly longer exorbital tooth in relation to the total carapace length $\left(\mathrm{ET} / \mathrm{CL}=0.27 \pm 0.09, \mathrm{~N}_{\mathrm{MR}}=26 ; \mathrm{ET} / \mathrm{CL}=0.18 \pm 0.01, \mathrm{~N}_{\mathrm{PC}}=28\right)$.

Relations of the chelae and the pleon were analyzed separately for adult males and females to account for their sexual dimorphism. Male chelae show highly significant differences between both populations, being shorter and higher in surface animals, while female claws show no significant differences (Table 1). The trend for longer appendages in cave specimens is thus only followed in male cheliped fingers. One possible explanation for this phenomenon would be that the marked differences in male chelar height (higher in surface animals) can be attributed to sexual selection in the form of visual display during courtship, which takes place in the surface population, but is not possible in the cave. 
Table 1 Comparison of morphometric relationships (mean \pm standard deviation; $n=$ sample size) of the Printed Circuit Cave and the Mouth River crab populations. Exclusively adult animals of both genders were measured. Statistical calculation based on unpaired two-tailed $t$ test. Significant results are shown in bold

\begin{tabular}{|c|c|c|c|c|c|}
\hline$\widehat{c}$ and $q$ & Printed Circuit Cave & Mouth River & $p$ & $t$ & $d f$ \\
\hline IOW/CW & $0.47 \pm 0.01(n=28)$ & $0.48 \pm 0.01(n=29)$ & 0.002 & -2.41 & 55 \\
\hline 4PpL/CW & $1.75 \pm 0.04(n=18)$ & $1.65 \pm 0.06(n=24)$ & $<0.0001$ & 6.49 & 40 \\
\hline $2 \mathrm{ML} / 2 \mathrm{MW}$ & $2.57 \pm 0.15(n=26)$ & $2.28 \pm 0.11(n=29)$ & $<0.0001$ & 8.18 & 53 \\
\hline $3 \mathrm{ML} / 3 \mathrm{MW}$ & $2.63 \pm 0.13(n=26)$ & $2.35 \pm 0.11(n=28)$ & $<0.0001$ & 8.93 & 52 \\
\hline $4 \mathrm{ML} / 4 \mathrm{MW}$ & $2.66 \pm 0.13(n=25)$ & $2.36 \pm 0.12(n=26)$ & $<0.0001$ & 8.8 & 49 \\
\hline $5 \mathrm{ML} / 5 \mathrm{MW}$ & $2.51 \pm 0.16(n=25)$ & $2.29 \pm 0.10(n=26)$ & $<0.0001$ & 5.91 & 49 \\
\hline ET/CL & $0.18 \pm 0.01(n=28)$ & $0.27 \pm 0.09(n=26)$ & $<0.0001$ & -5.16 & 52 \\
\hline$\widehat{o} \mathrm{PrL} / \mathrm{PrH}$ & $1.81 \pm 0.08(n=18)$ & $1.75 \pm 0.08(n=20)$ & 0.009 & 2.65 & 37 \\
\hline$\widehat{o} \mathrm{DaL} / \mathrm{PrH}$ & $1.17 \pm 0.05(n=18)$ & $1.11 \pm 0.05(n=20)$ & 0.0007 & 3.67 & 37 \\
\hline ○ PrL/PrH & $2.03 \pm 0.11(n=10)$ & $1.99 \pm 0.03(n=9)$ & 0.3 & 1.07 & 17 \\
\hline o DaL/PrH & $1.24 \pm 0.05(n=10)$ & $1.22 \pm 0.03(n=9)$ & 0.25 & 1.18 & 17 \\
\hline
\end{tabular}

In order to test for the overall differentiation between the two populations, a discriminant analysis was carried out using 14 sex-unrelated log-transformed variables and adding six specimens of $S$. windsor from the unconnected Quashies River as an outgroup. The dataset was subjected to canonical analyses as shown in Fig. 2. The discrimination between the groups was highly significant (Wilks' Lambda: $0.0299, F(28.74)=12.650, p<0.0001)$. All populations could be correctly classified with a likelihood of $100 \%$. The Mahalanobis distances are shorter between the Mouth River and the Printed Circuit Cave population than between both of these populations compared to the outgroup population from the Quashies River. The first canonical function (root1) accounted for $93.94 \%$ of the explained variance, the first two roots together for $100 \%$.

\subsubsection{Genetics}

A 1,059-basepair fragment of the mitochondrial Cox1 gene was amplified and sequenced for a total of 20 specimens from each population. Among the 40 sequences, a total of 16 different haplotypes and 19 variable nucleotide positions could be identified. The statistical parsimony network constructed with TCS illustrates the genetic distances among the haplotypes (ht) of $S$. windsor (Fig. 3). The common haplotypes ht $1(3 \times \mathrm{PC}, 4 \times \mathrm{MR})$, ht6 $(4 \times \mathrm{PC}, 3 \times \mathrm{MR})$, and ht7 $(2 \times \mathrm{PC}$, $3 \times \mathrm{MR}$ ) occur in both populations with similar frequencies. Ht1 can be regarded as the ancestral haplotype, because six other haplotypes seem to have diverged from it (Crandall and Templeton 1993). From those six haplotypes, three $(6,7,16)$ are again the starting point for more haplotypes. Ht4 shows the maximal distance to ht1. These two haplotypes are separated by eight substitutions. The largest distance between all recorded haplotypes is shown between ht 4 and ht13, which are separated by 13 substitutions (Fig. 3, Table 2). 


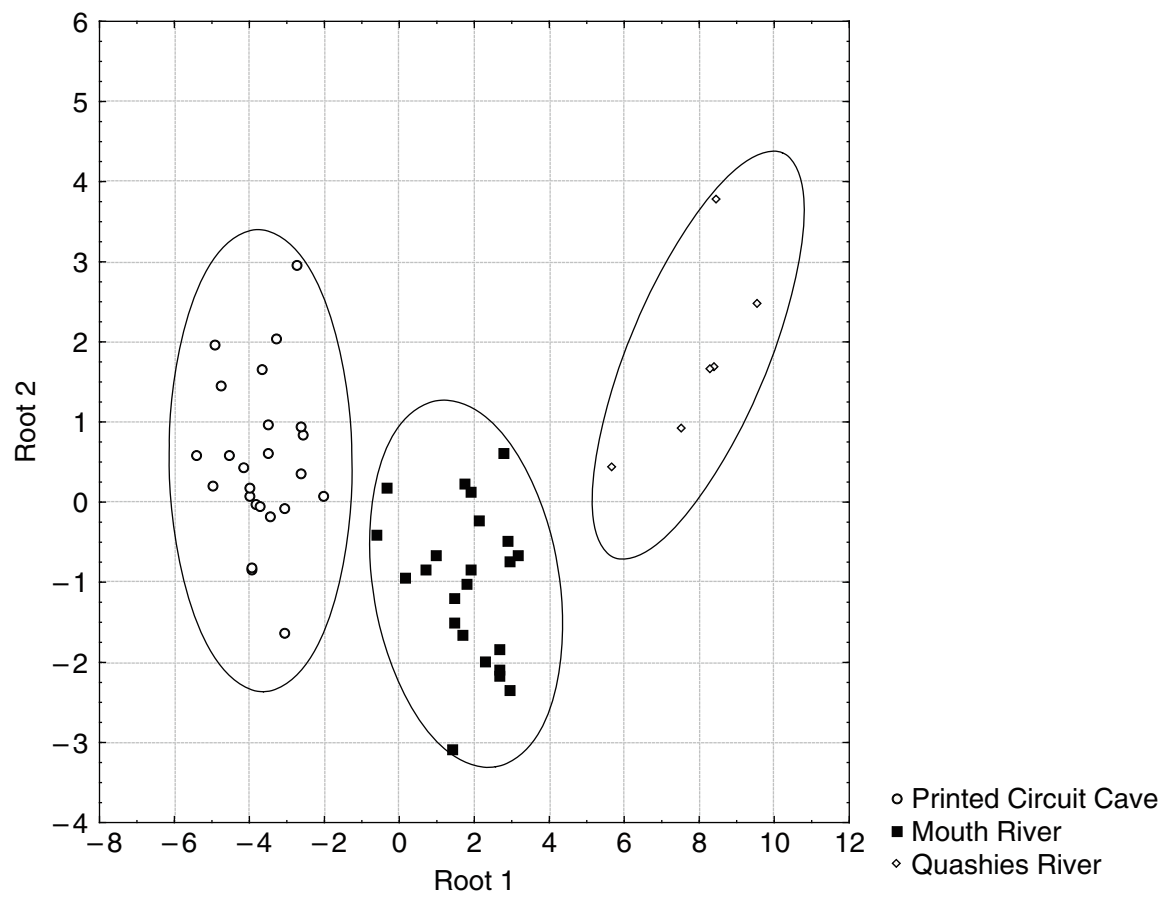

Fig. 2 Discriminant analysis showing morphometric differentiation between 53 specimens of Sesarma windsor (24 specimens, Printed Circuit Cave; 23, Mouth River; 6, Quashies River) according to 14 sex-unrelated log-transformed variables

Six haplotypes occur in both populations (1-4, 6-7) while five currently appear as private haplotypes for either the Printed Circuit Cave population $(5,8-11)$ or the Mouth River population (12-16). Among the haplotypes restricted to one of the two populations, the haplotypes ht12 and ht13 are the only ones to occur twice. The three most common haplotypes, ht1, ht6 and ht7 (accounting for $47.5 \%$ from the total sequences), are shared, and ht 6 and ht 7 are separated by single transitions from ht1. Transversions are found between shared haplotypes $(2,3,4)$ as well as in haplotypes so far restricted to the cave $(5,8,10)$. Four haplotypes result in an amino acid exchange according to the invertebrate codon usage (Table 2). Both populations are characterized by identical haplotype diversities of $h=0.88$ and maximum sequence divergence of 13 mutational steps $(1.23 \%)$ in the river population and 12 mutational steps $(1.13 \%)$ in the cave population. The analysis of molecular divergence using AMOVA showed that there is no significant genetic difference between the cave and the river population $(p=0.51)$. The overall $\phi_{\mathrm{ST}}$ of 0.09 indicates that gene flow between the populations is not restricted over longer time periods.

Likewise, three microsatellite markers failed to provide evidence for genetic differentiation between the cave population and the surface population. Originally designed for the bromeliad crab Metopaulias depressus Rathbun 1896, the microsatellite Met23 (Marcadé et al., unpublished) showed variability in the form of 
Fig. 3 Statistical parsimony network showing the genetic distances between haplotypes of the Mouth River population and the Printed Circuit Cave population of Sesarma windsor. The size of the circular area is equivalent to the frequency at which the haplotype occurs within the 40 examined specimens (Table 2). Each connecting line and each transverse smaller line illustrates a substitution. Transversions are shown with bold lines. Mouth River haplotypes are shown in green, Printed Circuit haplotypes in blue and haplotypes occurring in both populations in gray

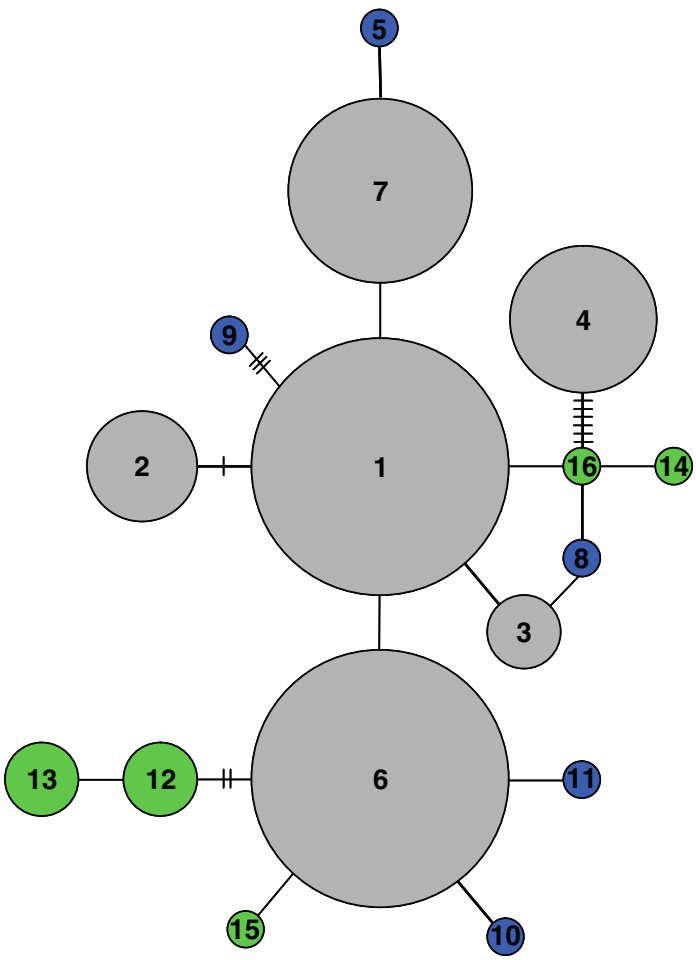

25 alleles, but their distribution among 50 individuals suggests extensive gene flow between the cave and the surface population $\left(F_{\mathrm{ST}}=0.0065, p>0.05\right)$ and a strong heterozygote deficiency $\left(F_{\text {IS }}=0.0065, p<0.001\right)$. Microsatellites MHA and MHE (Heine 2006) amplified regions with repeats, but they were of the same length in all tested individuals.

\section{Genotypic Diversification Within Three Species of Freshwater Crabs}

The adaptive radiation and consequent species diversity of terrestrial and freshwater crabs on Jamaica is not equalled by the crab faunas from the other Greater Antilles. Cuba, Hispaniola, and Puerto Rico; all have one or more species of endemic freshwater crabs belonging to the genus Epilobocera and the family Pseudothelphusidae. However, neither in terms of species numbers nor ecologically, are the freshwater crabs from these islands as diverse as the Jamaican fauna, despite the considerably larger size of some of these islands. Unlike the Sesarmidae, which are mostly coastal marine forms, the family Pseudothelphusidae is an old 


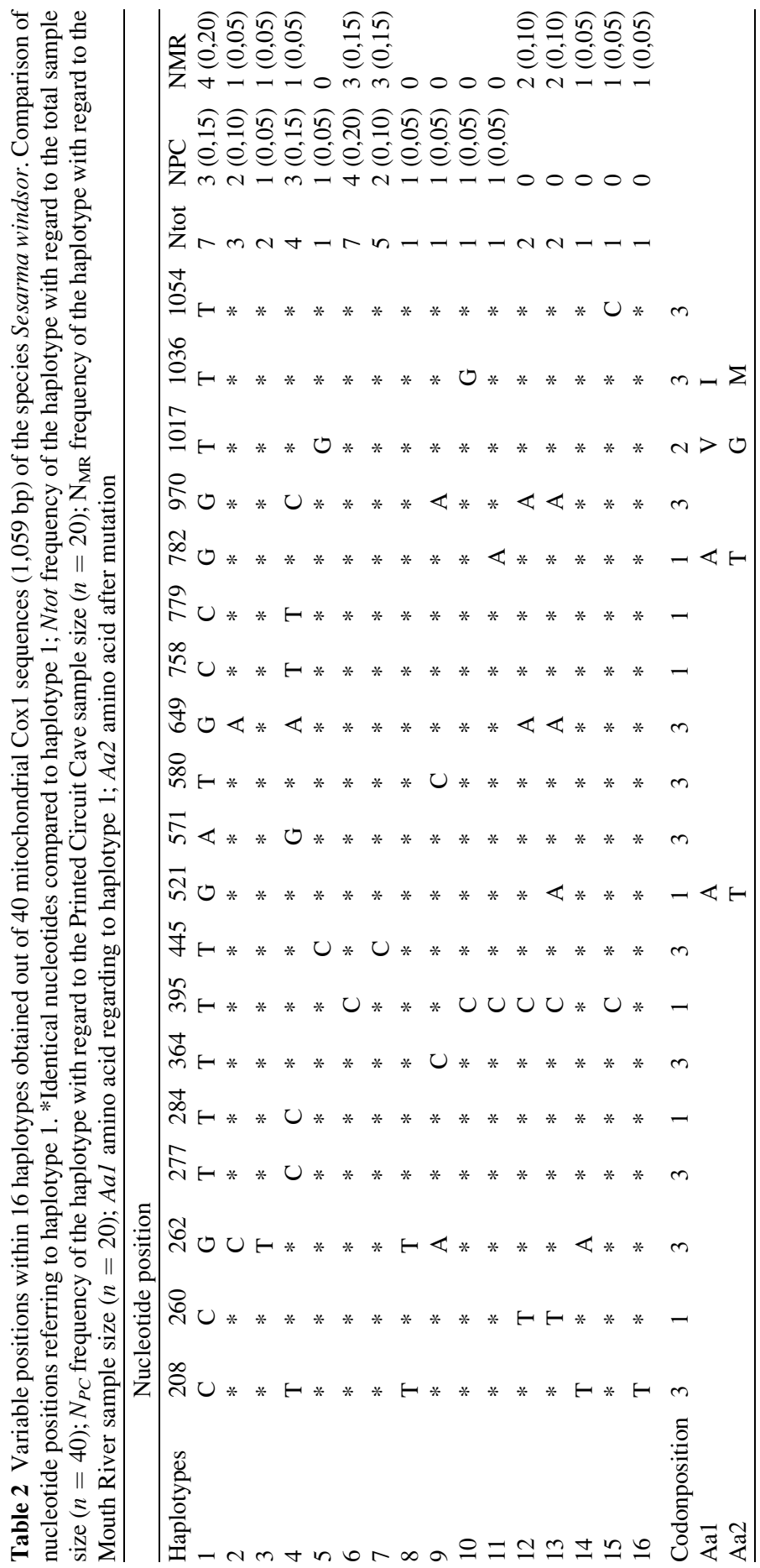


lineage of exclusively freshwater crabs distributed throughout the neotropics (northern Brazil to southern Mexico). While representatives of the Pseudothelphusidae probably colonized the Lesser Antilles rather recently from the South American mainland via the Aves Ridge (similar to the description in Iturralde and MacPhee 1999), the Greater Antilles (with the exception of Jamaica) have a much older and more derived fauna of freshwater crabs, which morphologically most resemble the pseudothelphusids from Yucatán (Mexico). Colonization in this case may have taken place by means of vicariance (as described in Hedges 2001), when the Caribbean Plate was pushed eastward between the two American Plates in the Early Tertiary (see maps in Buskirk 1985). Currently, there are seven recognized endemic species of Epilobocera on Cuba (Capolongo and Pretzmann 2002; Ng et al. 2008), two on Hispaniola, and one on Puerto Rico (Chace and Hobbs 1969; Rodríguez and Williams 1995). The absence of Epilobocera from Jamaica can be explained by the fact that this island was almost completely submerged during part of the Mid Tertiary (see Buskirk 1985).

Most rivers and mountain streams of the different Greater Antillean islands are very similar in terms of soils, vegetation, and temperature. They appear to represent comparable ecological niches, which is also recognizable by the presence of the same species of freshwater shrimp (e.g., Atya scabra, A. innocuous, Macrobrachium faustinum, $M$. carcinus, Xiphocaris elongata) in rivers of Cuba, Hispaniola, Jamaica, and Puerto Rico (Chace and Hobbs 1969). These shrimps have a marine larval development which allows dispersal among the Caribbean islands (Reuschel and Schubart, submitted). In contrast, the freshwater crabs have a direct (Pseudothelphusidae) or an abbreviated larval development (Sesarmidae) (Hartnoll 1964; Chace and Hobbs 1969; Schubart et al. 2000; Anger and Schubart 2005; González-Gordillo et al. 2010). This allows for independent evolution and radiations on the different islands. The question remains, why on Jamaica such a high diversity of freshwater and terrestrial crabs evolved in a much shorter time period (4.5 my, according to Schubart et al. 1998a) compared to the crab fauna of the other Greater Antilles, which had a ten-fold longer time for diversification. This question will be addressed by comparative population genetic analyses. Do species of Sesarma and Epilobocera differ in their intraspecific diversification? Results for three Jamaican species will be presented here, while diversification of freshwater crabs from the other Greater Antilles is dealt with elsewhere (Rivera and Schubart, submitted; Schubart et al., submitted) and summarized later in this chapter.

\subsection{Material and Methods}

For three endemic freshwater species of Sesarma from Jamaica, specimens were collected from all rivers where the crabs are known to occur (Fig. 1). Sesarma dolphinum Reimer et al. 1998 is present in rivers from westernmost Jamaica (parishes of Hanover and Westmoreland). For this species, samples were obtained from 13 localities corresponding to nine independent river systems. The Cabarita 
River is the largest river in the area with long tributaries in different elevated areas, but unsuitable habitat in the southern lowland where the tributaries merge. This species was selected to quantify genetic diversity and geographic heterogeneity in a relatively small area with many rivers that are known to be unconnected. This is not the case for Sesarma windsor Türkay and Diesel 1994 and Sesarma meridies Schubart and Koller 2005, which occur in rivers from the eastern Cockpit Country (parishes of Trelawny and Clarendon), with rivers draining to the north harboring $S$. windsor, while rivers draining to the south are inhabited by S. meridies. The latter species also occurs further to the east in the Rio Magno (St. Catherine Parish), a tributary of the Rio Cobre system, otherwise inhabited by Sesarma bidentatum Benedict 1892. Sesarma meridies is the most recently described species of Jamaican freshwater crab and currently also the youngest phylogenetic split (Schubart, unpublished). Its genetic and morphological distinction from $S$. windsor has been highlighted by Schubart and Koller (2005) with the help of DNA from two mitochondrial genes. However, it was not tested with nuclear markers whether these two closely related species may show signs of hybridization.

Between 1995 and 2005, more than 250 individuals from 20 different sampling sites were collected for this study. Whenever possible, a minimum of 10 individuals were collected per locality. Animals were killed on ice and transferred to $95 \%$ ethanol. DNA was extracted as described above (see 2.1). In this case, the complete nuclear ITS1-5.8SrRNA-ITS2 gene complex (ITS1-2) was amplified in order to compare the variable DNA of the non-coding internally transcribed spacers (ITS). The primers ITS-5 (here ITSL1) (5'-GGA AGT AAA AGT CGT AAC AAG G-3', White et al., 1990); ITSL1b (5'-GTC GTA ACA AGG TTT CCG TAG-3', new), ITSH1 (5'-TTC AGT CGC CCT TAC TAA GGG AAT CC-3'; new), and ITSH1b (5'-CCA GTT CAG TCG CCC TTA CT-3', new) nested within 18SrRNA (ITSL1 and L1b) and 28SrRNA (ITSH1 and H1b) were used. In addition, internal primers ITSL2 (5'-AAG AAT ACC AGA TAC ATC GAC AA-3'; new) and ITSH4 (5'- TTG TCG ATG TAT CTG GTA TTC TT-3'; new), located within the 5.8S rRNA, were occasionally applied. The resulting amplified fragments had a length between 1,200 and 1,400 base pairs (bp), due to several microsatellite repeat motives varying in length (see Harris and Crandall 2000). ITS1-2 clones were also obtained from single individuals of the mountain stream crab from the western and central Cockpit Country, Sesarma fossarum Schubart et al. 1997 and from the cave crab $S$. verleyi to be used as outgroups. Sequences of the different clones have been deposited in the EMBL database (FN395306-FN395315, FN395609-FN396100).

For PCR, standard $25-\mu \mathrm{l}$ reactions were used including $2.5 \mu \mathrm{l}$ of $10 \times$ buffer, $2.5 \mu \mathrm{l}$ of $1.25 \mathrm{mM}$ dNTPs, $0.5 \mu \mathrm{l}$ of both primers $(20 \mu \mathrm{M}), 2 \mu \mathrm{l}$ of $25 \mathrm{mM} \mathrm{MgCl}_{2}$, $1 \mu \mathrm{l}$ of $0.5 \mathrm{U} / \mu \mathrm{l}$ TAQ and $15 \mu \mathrm{l}$ of double distilled water. The reaction ran for 40 cycles with the program described in sect. 2.1.2, but 90 s elongation time and an annealing temperature of $50^{\circ} \mathrm{C}$. Positive amplifications were prepared for cloning by treatment with an A-Addition kit from Invitrogen (Carlsbad CA) to add polyA ends. Cloning was performed using the TOPO-TA cloning kit from Invitrogen. Colonies which had successfully included the vector with the PCR insert were picked and transferred to $50 \mu \mathrm{l}$ of $\mathrm{ddH}_{2} \mathrm{O}$. This solution was denatured for $10 \mathrm{~min}$ at 
$96^{\circ} \mathrm{C}$, and $1 \mu \mathrm{l}$ was used for a PCR with 35 cycles and $55^{\circ} \mathrm{C}$ as annealing temperature to control for cloning of the correct fragment. This PCR product was cleaned with PCR Cleanup Millipore plates (Millipore, Billerica, MA) and then cyclesequenced in both directions using standard protocols. Sequences were read with an automated ABI 3730 sequencer.

Sequence chromatograms were edited and proofread for possible errors with Chromas Lite http://www.technelysium.com.au/chromas_lite.html. An alignment was created with the ClustalW plugin of BioEdit (Hall 1999). This alignment was manually checked and modified, because microsatellite regions were not always correctly treated by the automated alignment. For further analysis, all alignment files were converted to the nexus file format. An important part of the information of ITS sequences is based on the elevated number of indel events, which should be considered phylogenetic signal according to Simmons and Ochoterena (2000). The indels are often due to microsatellite repetitive elements of varying lengths and point mutations in the non-coding ITS 1 and ITS 2 region, whereas the 5.8 rRNA region remained practically unmodified. To render the indels useful for all tree search methods, the simple indel coding method (Simmons et al. 2001) was used, which was calculated with the program GapCoder (Young and Healy 2003). Two datasets were maintained separately in order to address two slightly different questions. The dataset of all ITS1-2 clones from $S$. dolphinum was used to measure nuclear genetic intraspecific diversification in a species occurring in many unconnected rivers, but in a relatively small area. In contrast, the dataset including all ITS1-2 clones of $S$. windsor and $S$. meridies was used to test for possible hybridization in two closely related and morphologically similar species, which occur in rivers separated by few kilometers and which partly seep into the underground, with unknown subterranean connections. Accordingly, these datasets were analyzed separately using a network method for the preprocessed data obtained with GapCoder. The great amount of variation within the ITS dataset did not allow use of the statistical parsimony algorithm of the TCS software. Instead, the software Splitstree version 4 (Huson and Bryant 2006) was used for construction of the networks. Pairwise $F_{\mathrm{ST}}$ values among populations were calculated with Arlequin version 3.1 (Excoffier et al. 2005). For an overall phylogenetic interpretation of the data, all the ITS1-2 clones were finally combined. In this case, a Bayesian radiation tree was constructed with Mr. Bayes (Huelsenbeck \& Ronquist 2001) and confidence levels determined after running one million generations with four chains and a sample frequency of 100 .

\subsection{Results}

\subsubsection{Sesarma dolphinum}

232 clones from 32 individuals of Sesarma dolphinum were sequenced including the entire ITS1-2 region. Up to 15 successfully sequenced clones were included in this analysis, with an ITS sequence length of between 1,191 and 1,244 bp (after excluding flanking rDNA regions). This places this species in an intermediate 
position considering the length of ITS sequences found in decapod Crustacea (Harris and Crandall 2000). Two of the clones had large inserts with over $300 \mathrm{bp}$ and were excluded from the analysis. After the conversion of the alignment data with GapCoder, we obtained an alignment of 1,408 sites (415 variable/173 parsimony-informative including flanking regions) and 223 haplotypes. Only ten alleles occurred more than once and no allele more than twice. The corresponding minimum spanning network is presented in Fig. 4. Most prominent is the separate non-overlapping position of clones from individuals of the Deans Valley River and the Roaring River, both being southeastern populations of S. dolphinum. Next closest, and connecting to the other populations, are clones from the Flint River and the upper Cabarita River from the northeastern range of S. dolphinum. At the other extreme of the network are the clones from the New Savannah River from the southwestern range of the species, which also cluster closely together. Close and partly overlapping with New Savannah River are the clones from the Green Island, Morgan, Davis, and Lances Rivers, and both Lucea Rivers. These are the northwestern populations of $S$. dolphinum. A marked intraspecific geographic structure can thus be recognized by this network. This is confirmed by the analysis of molecular variance, which resulted in significant differences between all river systems except for the neighboring Green Island and Morgan Rivers (Table 3)

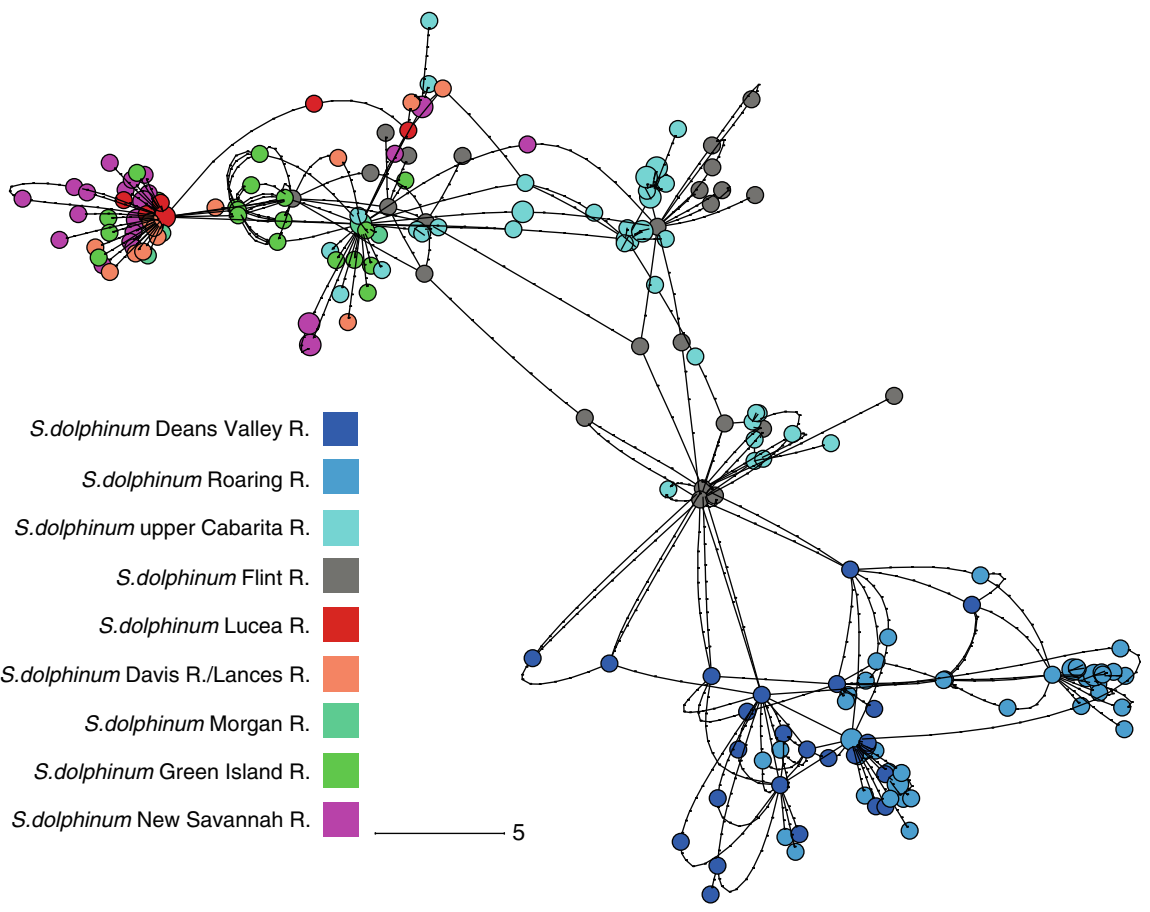

Fig. 4 Network constructed with Splitstree representing complete ITS1-5.8S-ITS2 alleles from different populations of Sesarma dolphinum 


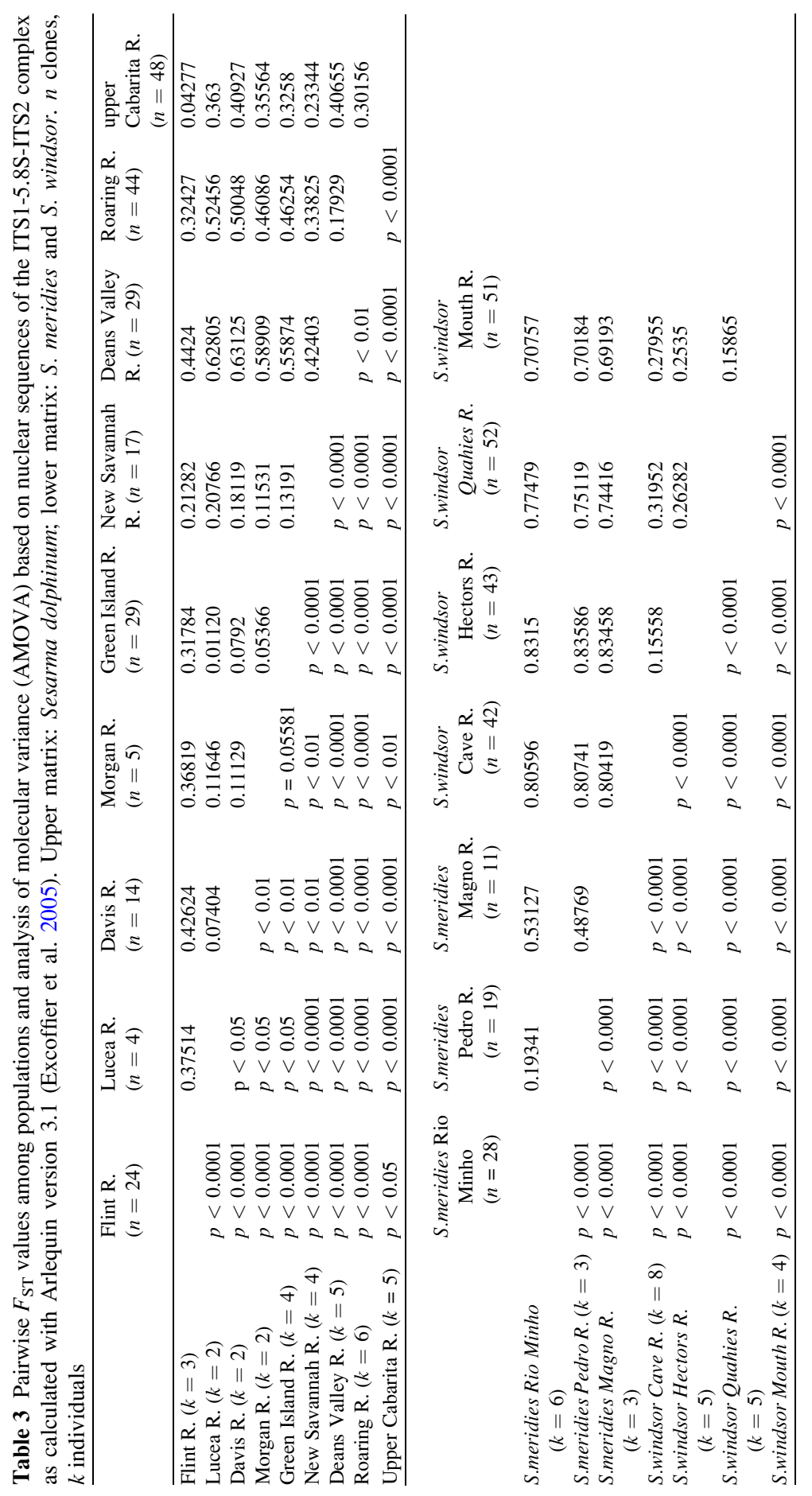


The pairwise $F_{\mathrm{ST}}$ reflect the degree of differentiation between the different populations and are in agreement with the network representation.

\subsubsection{Sesarma windsor and Sesarma meridies}

The ITS1-2 complex was also used to depict the genetic population structure of Sesarma windsor and Sesarma meridies from central Jamaica. Overall, 260 clones from 31 individuals were obtained. The length of the ITS gene in these species varied between 1,196 and 1,226 bp (after exclusion of flanking regions of rDNA). After gap-coding, the length of the aligned data was 1,427 sites (314 variable/142 parsimony-informative, including flanking regions) and revealed 23 haplotypes. Most haplotypes occurred only once and the most common haplotype was found 11 times. The minimum spanning network shown in Fig. 5 and the distance tree in Fig. 6 show that the two species are well separated into two well-delimited clouds which are connected by a simple long line of missing genotypes. This confirms species status for both species and refutes the possibility of hybridization, due to close ranges and possible subterranean contact. In both species, no division into the different river systems is readily recognizable, but certain parts of the network are dominated by specific river systems or sets of rivers. This is also true for the clones from the Rio Magno, a locality which is geographically most distant from all the other sampling points. AMOVA, in contrast, confirms significant genetic differentiation of all analyzed river systems (Table 3), confirming the high degree of intraspecific differentiation among Jamaican river crabs.

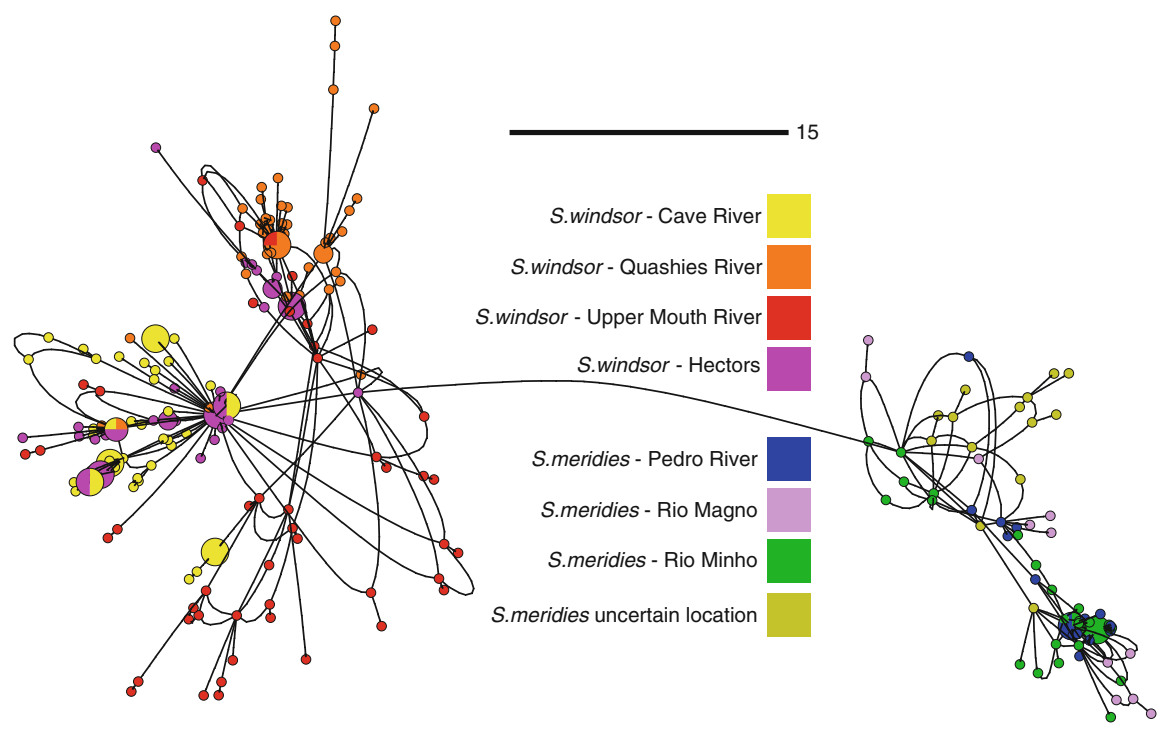

Fig. 5 Network constructed with Splitstree representing complete ITS1-5.8S-ITS2 alleles from different populations of Sesarma windsor and S. meridies 


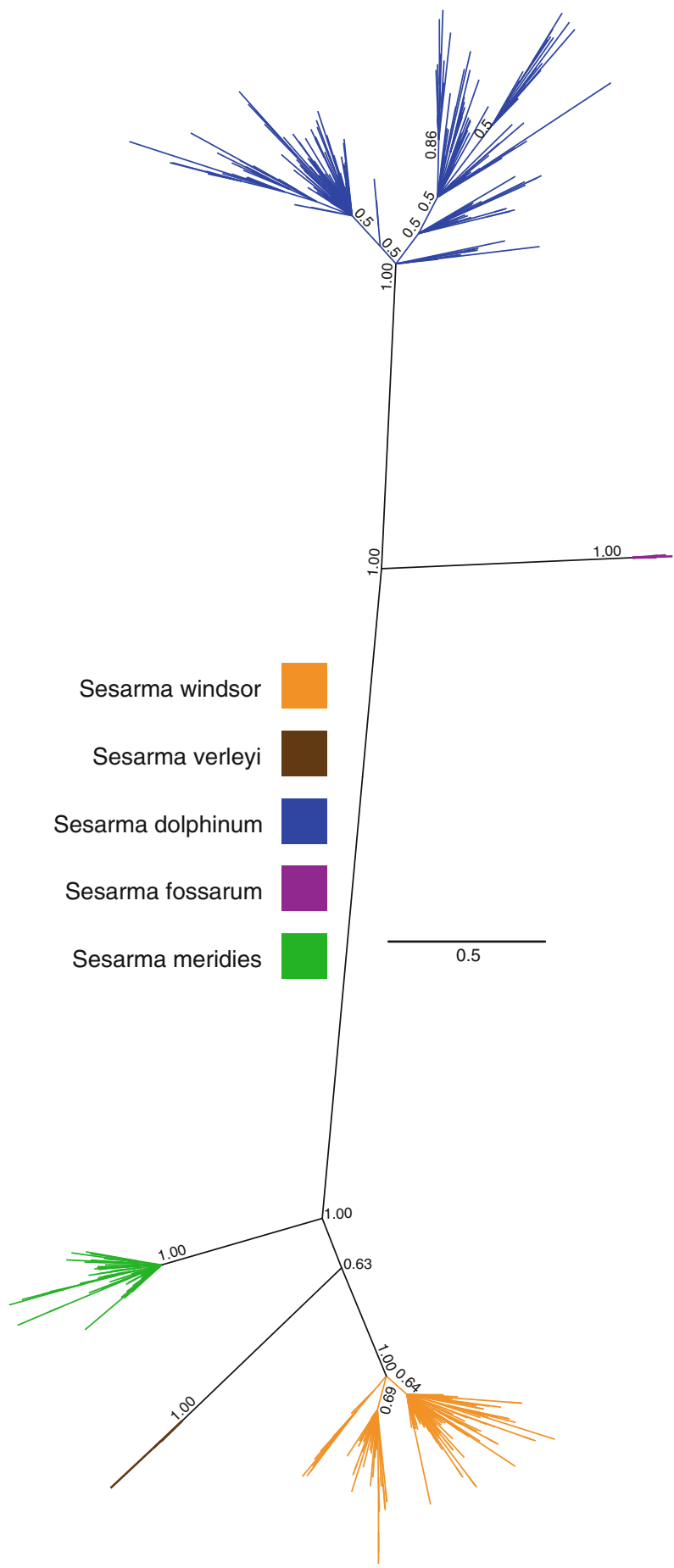

Fig. 6 Bayesian radiation tree constructed with MrBayes (one million generations) depicting phylogenetic relationships among ITS1-5.8S-ITS2 alleles of selected Jamaican endemic Sesarmidae 


\subsection{Discussion}

Most phylogeographic and many population genetic studies of animals are carried out with mitochondrial $(\mathrm{mt})$ sequences, especially of the cytochrome oxidase subunit 1 or the mt control region. This is primarily due to its overall higher mutation rate compared to the nuclear DNA. MtDNA is relatively stable and occurs in numerous copies per cell. This, and the fact that many universal primers are available for a number of genes, makes mtDNA relatively easy to amplify for a wide range of organisms. Due to its uni-parental inheritance (normally from the maternal side) and its consequent single-copied occurrence in most mitochondria, mtDNA is furthermore relatively easy to interpret. However, the discovery of selective sweeps, mitochondrial introgressions and nuclear copies of mtDNA (numts) have sounded a note of caution when interpreting phylogeographic or population genetic results exclusively based on mtDNA. The need for complimentary data from the nuclear genome is thus more urgent than ever. A number of molecular techniques are available that use information from the nuclear genome to distinguish between individuals or populations from within a species, like microsatellites, AFLPs, etc. Establishing microsatellite libraries is costly and sometimes tricky, the corresponding primers only being useful for a narrow range of species. Furthermore, the information from microsatellites as well as AFLPs is indirect, based on length differences or specific patterns of DNA fragmentation. Using the full sequence information in its original composition is still only possible by sequencing DNA. However, very few nuclear DNA regions are variable enough, but still universally amplifiable, to be used as intraspecific genetic markers. Internally transcribed spacers (ITS) represent an important exception. They are noncoding and therefore allow mutations without alteration of their function as buffers between the ribosomal genes $18 \mathrm{~S}$ rRNA, 5.8S rRNA, and 28 rRNA. These neighboring genes, on the other hand, provide highly conserved flanking regions in which suitable primers can be easily designed. The fact that some primers, which are commonly used for amplifying animal ITS, were originally designed for fungi is good evidence for the universality of the flanking regions. Two ITS genes are always found in the complex ITS1-5.8rRNA-ITS2, but the length of ITS1 and ITS2 varies tremendously among major taxa and to a lesser extent among species, individuals, or even copies within individuals. The main reason why ITS is not more frequently applied for population studies is probably precisely the fact that several copies of different lengths can be present within individuals, which results in overlapping signals when directly sequencing PCR products. Harris and Crandall (2000) found several short repetitive elements in the genome of the crayfish genera Orconectes and Procambarus, which were considered microsatellites according to their structure. This was also the case in both ITS genes of the Jamaican crabs studied here, as well as freshwater crabs of the family Pseudothelphusidae (see Schubart et al., submitted) and the family Parathelphusidae (see Kolbinger, Koller and Schubart, unpublished). To obtain clean sequences of the different alleles from one individual, PCR products need to be cloned prior to sequencing. When this was 
done in different insect (Culicidae by Wesson et al. 1992, Cicindela dorsalis by Vogler and DeSalle 1994, Coccinelidae by Schulenburg et al. 2001) or crustacean (cambarid crayfish by Harris and Crandall 2000, sesarmid and pseudothelphusid freshwater crabs in current study and Schubart et al., submitted) taxa, it turned out that more than two (from each parent) alleles were always present. It is known that the eukaryotic ribosomal DNA (rDNA) array typically consists of several hundred tandemly repeated copies of the transcription unit, encoding 18S-ITS1-5.8S-ITS228SrRNA. However, these copies are believed to be genetically homogenized by concerted evolution (e.g., Hillis et al. 1991). Williams et al. (1988) considered the possibility that homogenization via concerted evolution may take longer evolutionary times than commonly believed. Vogler and DeSalle (1994) found large intraindividual variation of ITS1-sequences in the tiger beetle Cicindela dorsalis, obscuring the phylogeographic signal within the Gulf of Mexico and along the Atlantic coast, and concluded that there is a lack of an efficient homogenization system. Also, the data by Harris and Crandall (2000) and the present study argue against at least rapidly acting concerted evolution in decapod crustaceans. While our ITS phylogeny allowed us to distinguish two closely related species, Sesarma windsor and $S$. meridies, its use to reveal phylogeographic structure is limited due to the fact that intra-individual variation was in part large enough to include sequences from the entire spectrum of variability within the species. We therefore agree with previous authors that the use of ITS for phylogeography and population genetics is diminished if multiple copies per individual are present and rDNA is not consistently homogenized by concerted evolution.

\section{Additional Findings and Outlook}

A relatively young adaptive radiation of land-dwelling crabs on a small tropical island offers many opportunities to study mechanisms and consequences of such a radiation. Not all the results can be presented within the frame of this book chapter; however, a few of them will be summarized here in order to show the progress after 1998, when Schubart et al. (1998a) provided final evidence that the Jamaican crab diversity is indeed the consequence of adaptive radiation.

Between 1994 and 2005, five new species of Jamaican freshwater crabs have been described based on morphology and genetics. Previously, they were all thought to belong to the then one described species of freshwater crab from Jamaican mountain streams, Sesarma bidentatum. The six species of freshwater crabs now recognized are allopatric and have non-overlapping distributional ranges that are arranged from west to east of the island as follows: S. dolphinum Reimer et al. 1998; S. fossarum Schubart et al. 1997; S. windsor Türkay and Diesel 1994; S. meridies Schubart and Koller 2005; S. bidentatum Benedict 1891; S. ayatum Schubart et al. 1998b. At first sight, these six species are of similar morphologies, but the specialist's eye will rapidly recognize important differences, like the aforementioned body shape of Sesarma windsor populations from caves, different 
degrees of pubescence on the walking legs, different tuberculation patterns on the claws, and also differently pronounced sexual dimorphism in some of the species, indicating different behaviors during courtship and/or male-male interactions. For example, the realization that crab females from the Rio Magno have clearly smaller chelae than males was the reason that they could immediately be identified as S. meridies, despite being found in a tributary of the Rio Cobre, which is otherwise inhabited by $S$. bidentatum, due to the fact that the latter species, and S. ayatum, have no or very faint sexual dimorphism. This could later be confirmed by other morphological and molecular results and currently constitutes the only example for two species being found in tributaries from the same larger river system (see Fig. 1), but without evidence for mixing as further confirmed in this study with the results from nuclear DNA of the Rio Magno population of S. meridies. Interestingly, $S$. meridies is still found in a western tributary and $S$. bidentatum in the eastern one, thus following the overall geographic trend of the species and allowing us to draw a distribution limit line between them. The lower Rio Cobre is a lowland river without much structure consisting of fast flowing and muddy waters during the rainy season. It is thus not suitable for mountain crabs, preventing a mixture of adults from both species in this part of the connected water system. However, it must be assumed that early ontogenetic stages of the crabs, which have no appendages as holdfasts (zoea larvae) or are too small and weak to withstand currents (juveniles), are regularly washed down into the main river and some of them later find their way back into the more suitable parts of the river system. Currently, it remains unclear how regularly this happens and whethter the clean separation of these two species is maintained by directed migration (smell of familiar tributaries) or by exclusive competition.

A similar case, but at the intraspecific level, could be demonstrated with the data presented here on population differentiation within Sesarma dolphinum. The Cabarita River system harbors crab populations in several of its tributaries of which four were sampled for this study (Fig. 1, Table 3). Two of these populations from the upper Cabarita River were genetically identical and closely related to the Flint River, which drains to the north but has its headwaters in immediate vicinity of the ones of the Cabarita River draining south from there. Another population from the Cabarita drainage is the one from the upper Morgan River, a tributary gathering its waters in the northwest area of the distribution of $S$. dolphinum. Interestingly, this population could not be statistically separated from the nearby Green Island River draining to the northeast (Table 3), but was clearly distinct from the other three populations from the Cabarita system. Finally, the population from the Roaring River in the southeast of the distributional range of S. dolphinum, and joining the Cabarita River in the southern plains, can also be genetically separated from the other populations of the Cabarita River and is instead more closely related to the nearby population from Deans Valley River with independent drainage into the ocean.

All these findings provide clear evidence that these crabs are more likely to migrate across the headwaters than in the large beds of the lowland rivers, where the corresponding tributaries merge. At the same time, it gives evidence for the clear geographic structure which is already recognizable at the intraspecific level and 
may explain the high diversification potential of the Jamaican crabs as one factor leading to the present species richness. Parallel to these studies, we are and have been carrying out phylogeographic and population genetic studies on diversification of the freshwater crabs from the other Greater Antilles. Thereby, it becomes evident that their intraspecific diversification potential is indeed reduced in comparison to the Jamaican crabs, despite being the much older lineage of freshwater crabs and probably having had much more time on the respective islands to evolve regional endemisms. Cook et al. (2008) studied phylogeography of the freshwater crab Epilobocera sinuatifrons (A. Milne-Edwards, 1866) from Puerto Rico with the mitochondrial Cox1 gene and found very limited differentiation for a freshwaterdwelling crab. This could be confirmed by current studies of Santl (2009) and Schubart et al. (submitted) using the more variable NDH1 mitochondrial DNA and ITS1-2 sequences in a similar pattern as shown in the current study. In this species, there is a gradient from western to eastern Puerto Rico, and populations from the extremes are significantly different from each other, but there is a clear isolation by recognizable distance pattern, when including intermediate populations. Rivera and Schubart (submitted) studied population genetics of the freshwater crab Epilobocera haytensis Rathbun, 1893 from Hispaniola with similar conclusions as for E. sinuatifrons. On one hand, there is significant genetic structure in 20 different rivers of the island and a clear west-east differentiation related to the Cordillera Central. However, this differentiation is lower than expected for such a large island and also shows isolation by distance patterns. Only a population of the Río Ocoa appears to have been isolated for a longer time, without deserving distinct species status. The number of species currently recognized for Cuba (Capolongo and Pretzmann 2002; $\mathrm{Ng}$ et al. 2008) is probably overestimated. E. armata is not a valid species and the genetic differences between some of the other species are not large enough to justify species status (Schubart et al., in progress). These findings suggest that crabs of the genus Epilobocera must maintain relatively constant gene flow between rivers, which is counteracting the regional differentiation, if freshwater crabs live in isolated river systems over extended periods (see, for example, Shih et al 2006). This gene flow is probably achieved by regular overland migrations, and this has indeed been observed repeatedly and recently documented by us with trapping experiments (Rivera and Schubart, unpublished).

The intra- and interspecific diversification of Jamaican freshwater crabs described here is the same as that found in many other marine, limnic, and terrestrial organisms, and follows the typical patterns known from "standard" allopatric differentiation and speciation: i.e., lack of gene flow followed by local specialization and genetic differentiation in the separated populations due to genetic drift, resulting in long-term reproductive isolation without necessary ecological specialization. The description of the five new species of freshwater crabs is thus the first instance in which the adaptive radiation of Jamaican crabs is documented as being accompanied or driven by "simple" allopatric speciation. It also demonstrates how difficult it is to separate the non-adaptive from adaptive radiations. A closer examination of some of the river species will show early adaptations to a new environment, as, for example, in the cave-living populations of Sesarma 
windsor (see above). Also, in the textbook examples of adaptive radiation, as in Darwin's finches and other organisms known to have evolved through adaptive radiations, allopatric separation in combination with the subsequent adaptations often plays a fundamental role as can be seen from the fact that many of the examples are from organisms living on nearby islands, where gene flow is highly reduced and organisms can in part specialize due to reduced homogenizing gene flow. Sympatric speciation can take place during adaptive radiations, but it is definitely not a condition for defining adaptive radiations.

The exact processes of speciation may be better understood if all the speciation events are clearly documented in a phylogenetic tree. However, as mentioned above, adaptive radiations are normally very fast processes, and different diversification processes (geographic and ecological) may take place within a single species at the same time leading to non-dichotomous net-like reticulate phylogenetic relationships. The phylogeny of the Jamaican crabs published in Schubart et al. (1998a) suggests such a fast radiation with a long branch and high bootstrap support leading to the monophyletic clade of all Jamaican endemic species, but short shared branches and low confidence values within the clade of Jamaican endemics. Currently, we are in the process of improving this phylogeny by adding sequences of more genes to this phylogenetic reconstruction. The most recent preliminary phylogeny based on more than 4,300 bp (12S, 16S, and 28S rRNA, 1,200 bp Cox1, and ITS1-5.8S-ITS2) strengthens the insight from earlier trees that neither the similar looking crabs from mountain streams nor the more specialized terrestrial forms are monophyletic, but that their diversification follows a strong geographic pattern (Schubart, in progress). That means that the allopatric differentiation in fresh waters played an important role from early on, but was accompanied by the evolution of ecologically more specialized forms that evolved regionally from the corresponding river species ancestor. For example, the rock rubble crab from the easternmost John Crow Mountains, Sesarma cookei Hartnoll 1971, is most closely related to a clade formed by the river crabs S. bidentatum (today mostly Blue Mountains) and S. ayatum (today exclusively John Crow Mountains) and not to the similar looking rock rubble crabs from central (S. jarvisi Rathbun 1914) and western (Sesarma sp.n.) Jamaica. Morphological convergence is thus another issue that needs to be taken into account when studying radiations and may be a factor in maintaining similar morphologies in the mountain stream species, despite their early divergence in the overall phylogenetic tree.

New endemic crab species have been regularly added to the list of the Jamaican fauna during the last years, and the question arises whether we have seen the end of it. Compared to the diversity of "real" terrestrial organisms like snails (Goodfriend 1986; Rosenberg and Muratov 2006), amphibians (Hedges 1989), and reptiles (Hedges and Burnell 1990), the Jamaican crabs are not an exceptionally speciesrich group. However, for a recent marine invader, they probably are. So far, all new Jamaican species have been described using morphological methods, sometimes aided by molecular results (e.g., Schubart \& Koller 1998b; Schubart and Koller 2005). However, in the future, it will become more and more common practice to recognize species solely based on their genetic differentiation. This way, Bond and 
Sierwald (2002) revealed cryptic species among Jamaican millipedes. For the Jamaican mountain stream crabs, most rivers have been sampled, and intraspecific diversity is being described for the six currently recognized species. Reimer et al. (1998), when describing $S$. dolphinum as new, noticed that animals from Galloway (Deans Valley River) had a slightly different morphology and considered the possibility of placing them into a separate subspecies. Our molecular results presented here, and additional ones based on mtDNA by Santl (2009), confirm the distinctness of the animals from Deans Valley River. Compared to the differences that we are finding between already described species (e.g., S. meridies and S. windsor), we do recognize a lower level of differentiation. However, the populations from the Deans Valley-Roaring River represent an evolutionary significant unit which is geographically, morphologically, and genetically separable from other units within S. dolphinum. Therefore a subspecies status may indeed be justifiable. Also, among the more specialized Jamaican species, population genetics are still revealing the possible existence of undescribed species. This is the case in the bromeliad crab Metopaulias depressus as indicated by Heine (2006) and Rivera (2007) and currently being investigated with nuclear markers. Even more pronounced species-level distinction is discernible in the snail shell crab Sesarma jarvisi, for which a new species is currently being described based on mitochondrial and nuclear markers as well as on morphology (Schubart, in preparation). This will add to the spectacular ecological and biological diversity of Jamaican crabs, which have descended from a single lineage of marine ancestor approximately 4.5 million years ago and will not stop in their divergence and long-term species formation, if human environmental destruction, as currently seen in Jamaican forests, does not destroy part of the diversity before it can even be described and appreciated.

Acknowledgements The first author is especially grateful to his former advisor Rudi Diesel who introduced him to the world of the Jamaican crabs and contributed decisively to this manuscript with many early discussions and collecting trips. We would also like to thank all the other people who helped collect in the field over the years, among them Jens Reimer, Gernot Bäurle, Martina Schuh, Gary Rosenberg, Rene Brodie, Klaus Anger, Silke Reuschel, and Luise Heine, as well as the Discovery Bay Marine Laboratory and the University of the West Indies for continuing support. Special thanks are also due to the team of the Crandall Laboratory, who supported two of us, while cloning a maximum of ITS alleles in relatively short time intervals and associated support from the US National Science Foundation (EF-0531762). This study was financially supported by research project Schu 1460/3 to CDS within the DFG Priority Program 1127 "Adaptive Radiation-Origin of Biological Diversity".

\section{References}

Anger K, Schubart CD (2005) Experimental evidence of food-independent larval development in endemic Jamaican freshwater-breeding crabs. Physiol Biochem Zool 78:246-258

Avise JC (2004) Molecular markers, natural history, and evolution. Sinauer Associates, Sunderland, Massachusetts

Benedict JE (2004) Decapod Crustacea of Kingston Harbour. Johns Hopkins University Circular $11: 77$ 
Bond JE, Sierwald P (2002) Cryptic speciation in the Anadenobolus excisus millipede species complex on the island of Jamaica. Evolution 56:1123-1135

Buskirk R (1985) Zoogeographic patterns and tectonic history of Jamaica and the northern Caribbean. J Biogeo 12:445-461

Cabot EL, Beckenbach AT (1989) Simultaneous editing of multiple nucleic acid and protein sequences with ESEE. Comp Appl Biosci 5:233-234

Capolongo D, Pretzmann G (2002) Süßwasserkrabben von Cuba. Agemus Nachrichten 67b:1-4

Chace Jr FA, Hobbs Jr HH (1969) The freshwater and terrestrial decapod crustaceans of the West Indies with special reference to Dominica. In: Bredin-Archbold-Smithsonian Biological Survey of Dominica. Bull US Natl Mus 292:1-258

Clement M, Posada D, Crandall K (2000) TCS: a computer program to estimate gene genealogies. Mol Ecol 9:1657-1660

Cook BD, Pringle CM, Hughes JM (2008) Phylogeography of an island endemic, the Puerto Rican freshwater crab (Epilobocera sinuatifrons). J Hered 99:157-164

Crandall KA, Templeton AR (1993) Empirical tests of some predictions from coalescent theory with applications to intraspecific phylogeny reconstruction. Genetics 134:959-969

Darwin C (1845) Journal of researches into the natural history and geology of the countries visited during the voyage of H.M.S. Beagle round the world, under the Command of Capt. Fitz Roy, R.N, 2nd edn. John Murray, London

Darwin C (1859) On the origin of species by means of natural selection, or the preservation of favoured races in the struggle for life, 1st edn. John Murray, London

Diesel R (1997) Maternal control of calcium concentration in the larval nursery of the bromeliad crab, Metopaulias depressus (Grapsidae). Proc R Soc Lond B 264:1403-1406

Diesel R, Schubart CD (2000) Die außergewöhnliche Evolutionsgeschichte jamaikanischer Felsenkrabben. Biologie in unserer Zeit 30:136-147

Diesel R, Schubart CD (2007) The social breeding system of the Jamaican bromeliad crab Metopaulias depressus. In: Duffy JE, Thiel M (eds) Evolutionary ecology of social and sexual systems: Crustaceans as model organisms. Oxford University Press, New York, pp 365-386

Excoffier L, Laval G, Schneider S (2005) Arlequin ver. 3.1: An integrated software package for population genetics data analysis. Evol Bioinf 1:47-50

González-Gordillo JI, Anger K, Schubart CD (2010) Morphology of the larval and first juvenile stages of two Jamaican endemic crab species with abbreviated development, Sesarma windsor and Metopaulias depressus (Decapoda: Brachyura: Sesarmidae). J Crust Biol 30:101-121

Goodfriend GA (1986) Radiation of the land snail genus Sagda (Pulmonata: Sagdidae): comparative morphology, biogeography and ecology of the species of north-central Jamaica. Zool J Linn Soc 87:367-398

Hall TA (1999) BioEdit: a user-friendly biological sequence alignment editor and analysis program for Windows 95/98/NT. Nucleic Acids Symp Ser 41:95-98

Harris DJ, Crandall KA (2000) Intragenomic variation within ITS1 and ITS2 of freshwater crayfishes (Decapoda: Cambaridae): implications for phylogenetic and microsatellite studies. Mol Biol Evol 17:284-291

Hartnoll RG (1964) The freshwater grapsid crabs of Jamaica. Proc Linn Soc Lond 175:145-169

Hartnoll RG (1971) Sesarma cookei n. sp., a grapsid crab from Jamaica (Decapoda, Brachyura). Crustaceana 20:257-262

Hedges SB (1989) An island radiation: allozyme evolution in Jamaican frogs of the genus Eleutherodactylus (Leptodactylidae). Carib J Sci 25:123-147

Hedges SB (2001) Caribbean biogeography: an overview. In: Woods CA, Sergile FE (eds) Biogeography of the West Indies: patterns and perspectives. CRC Press, Boca Raton, Florida

Hedges SB, Burnell KL (1990) The Jamaican radiation of Anolis (Sauria: Iguanidae): An analysis of relationships and biogeography using sequential electrophoresis. Carib J Sci 26:31-44

Heine L (2006) Genetische Untersuchung der Sozialstruktur und zur Phylogeographie bei der Bromelienkrabbe Metopaulias depressus (Decapoda: Brachyura). Diploma thesis, Universität Regensburg 
Hillis DM, Moritz C, Porter A, Baker RJ (1991) Evidence for biased gene conversion in concerted evolution of ribosomal DNA. Science 251:308-310

Huber SK, de Leon LF, Hendry AP, Bermingham E, Podos J (2007) Reproductive isolation of sympatric morphs in a population of Darwin's finches. Proc R Soc Lond B 274:1709-1714

Huelsenbeck JP, Ronquist F (2001) MRBAYES: Bayesian inference of phylogenetic trees. Bioinformatics 17:754-755

Huson DH, Bryant D (2006) Application of phylogenetic networks in evolutionary studies. Mol Biol Evol 23:254-267

Iturralde MA, MacPhee RDE (1999) Paleogeography of the Caribbean region: implications for Cenozoic biogeography. Bull Am Mus Nat Hist 238:1-95

Marcade I, Klinkicht M, Diesel R (unpublished) Larvae dumping in the bromeliad crab, Metopaulias depressus (Decapoda: Grapsidae): Mothers care for unrelated young

Mathews LM, Schubart CD, Neigel JE, Felder DL (2002) Genetic, ecological, and behavioural divergence between two sibling snapping shrimp species (Crustacea: Decapoda: Alpheus). Mol Ecol 11:1427-1437

Neigel JE, Avise JC (1986) Phylogenetic relationships of mitochondrial DNA under various models of speciation. In: Nevo E, Karlim S (eds) Evolutionary processes and theory. Academic, New York, pp 515-534

Ng PKL, Guinot D, Davie PJF (2008) Systema Brachyurorum: Part I. An annotated checklist of extant brachyuran crabs of the world Raffles Bull Zool Suppl 17:1-286

Palumbi SR, Martin A, Romano S, McMillan WO, Stice L, Grabowski G (1991) The simple fool's guide to PCR. A collection of PCR protocols, version 2. University of Hawaii, Honolulu

Rathbun MJ (1896) Description of a new genus and four new species of crabs from the West Indies. Proc US Natl Mus 19:141-144

Rathbun MJ (1914) New species of crabs of the families Grapsidae and Ocypodidae. Proc US Natl Mus 47:69-85

Reimer J, Schubart CD, Diesel R (1998) Description of a new freshwater crab of the genus Sesarma Say, 1817 (Brachyura: Grapsidae: Sesarminae) from western Jamaica. Crustaceana 71:186-196

Reuschel S, Schubart CD (submitted) Genetic variability in the freshwater shrimp Xiphocaris elongata (Crustacea: Caridea) does not reflect morphological or geographical patterns

Rivera NT (2007) Evolution of intraspecific diversity: a comparison of genetic and geographic structure in Epilobocera haytensis and Metopaulias depressus (Crustacea: Decapoda: Brachyura). Diploma thesis, Universität Regensburg

Rivera NT, Schubart CD (submitted) Phylogeography of the freshwater crab Epilobocera haytensis (Brachyura: Pseudothelphusidae) from Hispaniola reveals limited gene flow among different river systems

Rodríguez G, Williams AB (1995) Epilobocera wetherbeei, a new species of freshwater crab (Decapoda: Brachyura: Pseudothelphusidae) from Hispaniola. Proc Biol Soc Wash 108:76-83

Rosenberg G, Muratov IV (2006) Status report on the terrestrial Mollusca of Jamaica. Proc Acad Nat Sci Philadelphia 155:117-161

Santl T (2009) Comparative diversification potential of an old and a young lineage of freshwater crabs on two Caribbean islands explained at the population level. PhD Dissertation, Universität Regensburg

Schluter D (2000) The ecology of adaptive radiations. Oxford University Press, Oxford

Schubart CD (2009) Mitochondrial DNA and decapod phylogenies; the importance of pseudogenes and primer optimization. In: Martin JW, Crandall KA, Felder DL (eds) Crustacean Issues 18: Decapod Crustacean Phylogenetics. Taylor \& Francis/CRC Press, Boca Raton, Florida, pp 47-65

Schubart CD, Cuesta JA, Diesel R, Felder DL (2000) Molecular phylogeny, taxonomy, and evolution of nonmarine lineages within the American grapsoid crabs (Crustacea: Brachyura). Mol Phylogenet Evol 15:179-190

Schubart CD, Diesel R (1999) Osmoregulation and the transition from marine to freshwater and terrestrial life: a comparative study of Jamaican crabs of the genus Sesarma. Arch Hydrobiol 145:331-347 
Schubart CD, Diesel R, Hedges SB (1998a) Rapid evolution to terrestrial life in Jamaican crabs. Nature 393:363-365

Schubart CD, Huber MGJ (2006) Genetic comparisons of German populations of the stone crayfish, Austropotamobius torrentium (Crustacea: Astacidae). Bull Franç Pêche Piscic 380-381:1019-1028

Schubart CD, Koller P (2005) Genetic diversity of freshwater crabs (Brachyura: Sesarmidae) from central Jamaica with description of a new species. J Nat Hist 39:469-481

Schubart CD, Reimer J, Diesel R (1998b) Morphological and molecular evidence for a new endemic freshwater crab, Sesarma ayatum sp. n., (Grapsidae, Sesarminae) from eastern Jamaica. Zool Scr 27:373-380

Schubart CD, Reimer J, Diesel R, Türkay M (1997) Taxonomy and ecology of two endemic freshwater crabs from western Jamaica with the description of a new Sesarma species (Brachyura: Grapsidae: Sesarminae). J Nat Hist 31:403-419

Schubart CD, Rivera NT, Crandall KA, Santl T (submitted) Comparing phylogeographic structure of freshwater crabs from two Caribbean islands: Puerto Rico versus Jamaica. In: Held C, Koenemann S, Schubart CD (eds) Crustacean Issues 19: Phylogeography and population genetics in Crustacea. Taylor \& Francis/CRC Press, Boca Raton, Florida

Schulenburg JHGvd, Hancock JM, Pagnamenta A, Sloggett JJ, Majerus MEN, Hurst GDD (2001) Extreme length and length variation in the first ribosomal internal transcribed spacer of ladybird beetles (Coleoptera: Coccinellidae). Mol Biol Evol 18:648-660

Shih H-T, Hung HC, Schubart CD, Chen CA, Chang H-W (2006) Intraspecific diversity of the endemic freshwater crab Candidiopotamon rathbunae (Crustacea: Decapoda, Brachyura, Potamidae) reflects five million years of geological history of Taiwan. J Biogeo 33:980-989

Simmons MP, Ochoterena H (2000) Gaps are characters in sequenced-based phylogenetic analyses. Syst Biol 49:369-381

Simmons MP, Ochoterena H, Carr TG (2001) Incorporation, relative homoplasy, and effect of gap characters in sequence-based phylogenetic analysis. Syst Biol 50:454-462

Sulloway FJ (1982) Darwin and his finches: the evolution of a legend. J Hist Biol 15:1-53

Templeton AR, Crandall KA, Sing CF (1992) A cladistic analysis of phenotypic associations with haplotypes inferred from restriction endonuclease mapping and DNA sequence data. III. Cladogram estimation. Genetics 132:619-633

Türkay M, Diesel R (1994) Description of a new species of Sesarma from Jamaica with notes on its occurrence and biology (Crustacea: Decapoda: Brachyura). Senckenberg Biol 74:157-161

Vogler AP, DeSalle R (1994) Evolution and phylogenetic information content of the ITS-1 region in the tiger beetle Cicindela dorsalis. Mol Biol Evol 11:393-405

Wesson DM, Porter CH, Collins FH (1992) Sequence and secondary structure comparisons of ITS rDNA in mosquitoes (Diptera: Culicidae). Mol Phylogenet Evol 1:253-269

White TJ, Bruns T, Lee SW, Taylor G (1990) In: White TJ, Innis M, Gelfand DH, Sninsky JJ, Innis MA (Eds) PCR protocols: A guide to methods and applications. Academic, San Diego, 1990, pp 315-324

Williams SC, DeBry RW, Feder JL (1988) A commentary on the use of ribosomal DNA in systematic studies. Syst Zool 37:60-62

Young ND, Healy J (2003) GapCoder automates the use of indel characters in phylogenetic analysis. BMC Bioinformatics 4:1-6 